\title{
Clinical Implications of Electrocardiograms for Patients With Non-ST-Segment Elevation Acute Coronary Syndromes in the Interventional Era
}

\author{
Masami Kosuge, MD; Kazuo Kimura, MD
}

\begin{abstract}
In patients with non-ST-segment elevation acute coronary syndromes, early risk stratification is crucial for appropriate management of this condition and for deciding whether early invasive strategies should be adopted. The electrocardiogram (ECG) has been extensively used for risk stratification, and the presence of ST-segment depression is an especially strong predictor of poor outcomes. Furthermore, quantitative analysis of ST-segment depression, ie, the degree and extent of ST-segment depression, and the time from symptom onset to the evaluation of ECG provide important information on prognosis. ST-segment elevation in lead $\mathrm{aVR}$ in addition to ST-segment depression in other leads is a very valuable marker of left main and/or 3-vessel disease. This review explores the clinical importance of the ECG in the current interventional era. (Circ J 2009; 73: 798-805)
\end{abstract}

Key Words: Acute coronary syndrome; Diagnosis; Electrocardiogram; Prognosis

$\mathbf{P}$ atients with non-ST-segment elevation acute coronary syndromes (NSTE-ACS) are heterogeneous with regard to both the underlying pathophysiology and the future risk of cardiac events! Early risk stratification is crucial for appropriate management of this condition and for deciding whether early invasive strategies should be adopted? Because of its simplicity, safety, widespread availability and low cost, the electrocardiogram (ECG) has been extensively used for risk stratification. The ECG plays a central role in diagnostic and triage pathways for NSTEACS and provides important prognostic information in the current interventional era.

\section{Importance of ECG in Risk Stratification}

Two treatment strategies have emerged for the early management of NSTE-ACS: one strategy is invasive, and the other is conservative. General consensus has been reached that patients at higher risk benefit more from early invasive strategies, increasing the importance of appropriate risk stratification. Recently, biomarkers of myocardial damage (troponin), inflammation (C-reactive protein), hemodynamic stress (brain natriuretic peptide, $\mathrm{N}$-terminal pro-brain natriuretic peptide) and renal function (creatinine) have also been linked to the risk of subsequent cardiac events ${ }^{3-5}$ However, the GUSTO-IV (Global Utilization of Strategies to Open Occluded Arteries-IV ACS) trial of 7,800 patients with NSTE-ACS has highlighted the striking prognostic value of ST-segment depression on admission as compared

(Received December 11, 2008; revised manuscript received December 23, 2008; accepted December 25, 2008; released online April 6, 2009) Division of Cardiology, Yokohama City University Medical Center, Yokohama, Japan

Mailing address: Masami Kosuge, MD, Division of Cardiology, Yokohama City University Medical Center, 4-57 Urafune-cho, Minami-ku, Yokohama 232-0024, Japan. E-mail: masami-kosuge@ pop06.odn.ne.jp

All rights are reserved to the Japanese Circulation Society. For permissions, please e-mail: cj@j-circ.or.jp with independent factors, including expanded biomarker profiles as well as traditional risk factors (Figure 1)? The ECG thus continues to have important roles in prognosis as well as in diagnosis and selection of the optimal treatment strategy in patients with NSTE-ACS.

\section{ST-Segment Depression}

ST-segment changes are considered the most important electrocardiographic feature during acute myocardial ischemia. In patients with transmural ischemia, ST-segment elevation is present in leads facing the site of ischemia. Therefore, the ischemia-related artery can be predicted on the basis of the leads showing ST-segment elevation during ischemic attacks. Whereas in many patients with non-transmural ischemia, ST-segment depression occurs in leads $\mathrm{V}_{4}$ to V6 leads (mainly in lead V5) independently of the ischemiarelated artery, in which underlying mechanism remains unclear. It is thus difficult to predict the ischemia-related artery on the basis of these leads. On exercise thallium myocardial scintigraphy, however, the site of a reversible decrease in blood flow corresponds to the region supplied by the ischemia-related artery, even in patients who have ST-segment depression in leads $\mathrm{V}_{4}$ to $\mathrm{V}_{6}$ (primarily lead V5) during myocardial ischemia.

The presence of acute ischemic changes on the admission ECG has been associated with a higher risk of cardiac events; ST-segment depression is an especially strong predictor of poor outcomes in patients with NSTE-ACS $3,6-15$ The presence of even minimal $(0.05 \mathrm{mV})$ ST-segment depression has been shown to be independently associated with adverse outcomes? Furthermore, the degree and extent of ST-segment depression, not only its presence or absence, strongly correlate with the severity and outcomes of coronary artery disease, $, 7,12-14$ Increased mortality has been associated with increased cumulative ST-segment depression or an increased number of leads with ST-segment depression on admission in patients with NSTE-ACS. A meta-analysis of 12,030 patients with stable coronary artery 


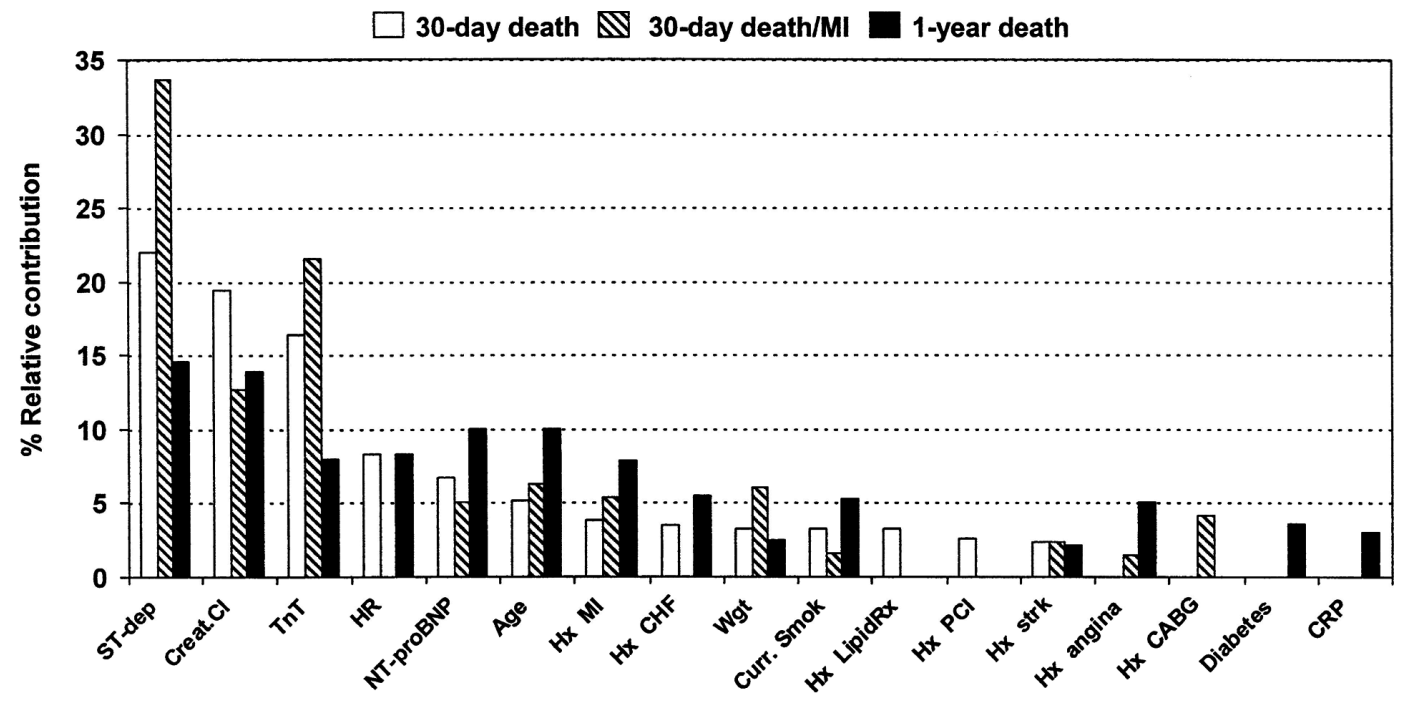

Figure 1. Relative contributions of significant, independent factors to the prediction of 30-day death, 30-day death/myocardial infarction (MI), and 1-year death. ST-segment depression on admission had a very high prognostic value even after considering independent factors such as expanded biomarker profiles in addition to traditional risk factors in 7,800 patients with non-ST-segment elevation acute coronary syndromes (NSTE-ACS) in the GUSTO-IV trial (Reproduced with permission from J Am Coll Cardiol 2006; 48: 939-947). Creat Cl, creatinine clearance; CRP, C-reactive protein; Curr Smok, current smoker; HR, heart rate; Hx angina, history of angina pectoris; Hx CABG, history of coronary artery bypass graft; Hx CHF, history of congestive heart failure; Hx MI, history of MI; Hx LipidRx, history of hyperlipidemic therapy; $\mathrm{Hx}$ PCI, history of percutaneous coronary intervention; Hx strk, history of stroke; NT-proBNP, N-terminal pro-brain natriuretic peptide; ST-dep, ST-segment depression; TnT, troponin T; Wgt, weight.

Table. Differences in Treatment Outcomes at 1 Year: Patients Classified According to Summed ST-Segment Deviation and Total Number of Leads With ST-Segment Deviation

\begin{tabular}{lccc}
\hline & Noninvasive strategy & $\begin{array}{c}\text { Invasive strategy } \\
\text { Adjusted odds ratio* } \\
(95 \% \mathrm{CI})\end{array}$ \\
\hline $\begin{array}{l}\text { Endpoint: death/myocardial infarction } \\
\text { Summed ST-segment deviation }\end{array}$ & & & \\
$\quad 0-0.25 \mathrm{mV}$ & $9.3 \%$ & $11.8 \%$ & $1.26(0.70-2.28)$ \\
$\quad 0.30-0.55 \mathrm{mV}$ & $13.3 \%$ & $6.2 \%$ & $0.42(0.23-0.80)$ \\
$\quad \geq 0.6 \mathrm{mV}$ & $19.4 \%$ & $9.5 \%$ & $0.41(0.24-0.70)$ \\
Number of leads with ST-segment deviation & $9.1 \%$ & $10.0 \%$ & $1.13(0.65-1.97)$ \\
$\quad 0-4$ leads & $15.7 \%$ & $8.0 \%$ & $0.45(0.25-0.81)$ \\
5-7 leads & $19.2 \%$ & $13.5 \%$ & $0.36(0.51-1.43)$ \\
$\quad \geq 8$ leads &
\end{tabular}

Modified reproduced with permission from J Am Coll Cardiol 2003; 41: 905-915.

*Adjusted for age, gender, previous myocardial infarction, diabetes, hypertension, smoking status, and troponin T.

$\mathrm{CI}$, confidence interval.

disease enrolled in 60 studies demonstrated that the amount of ST-segment depression during exercise stress testing is strongly associated with critical coronary artery disease, such as left main and/or 3-vessel disease (LM/3VD)! ${ }^{16}$ This finding could be extended to ST-segment changes on admission in patients with NSTE-ACS. The increased mortality in patients with higher ST-segment depression might be explained by their increased severity of coronary artery disease, and such patients with higher ischemic burden derive a good deal of benefit, as reflected in decreased mortality and morbidity, from invasive treatment strategies (Table) $)^{13,14}$ Quantitative electrocardiographic analysis thus provides important information on prognosis and expected benefits of treatment. In addition, the time from symptom onset to the evaluation of ECG appears to have an important impact on its prognostic value. Kaul et al demonstrated that patients with ST-segment depression for more than $6 \mathrm{~h}$ after symptom onset have a higher risk of death or myocardial infarction at 6 months than those with ST-segment depression within $6 \mathrm{~h}$ of symptom onset. ${ }^{14}$ It was demonstrated that among NSTE-ACS patients with ST-segment depression on the admission ECG, those with persistent ST-segment depression $6 \mathrm{~h}$ after admission despite intensive medical treatment have a higher risk of adverse events at 30 days? Such patients have higher frequencies of multivessel disease, severe stenosis, visible thrombi and complex culprit lesions. Prolonged as well as profound ST-segment depression may be indicative of more severe and/or unstable coronary artery disease. Serial analysis of ECGs can provide additional information that can enhance the accuracy of predicting outcomes in patients with NSTE-ACS.

\section{ST-Segment Elevation in Lead aVR}

Previous most studies assessing the clinical significance of the admission ECG in patients with NSTE-ACS have 
A

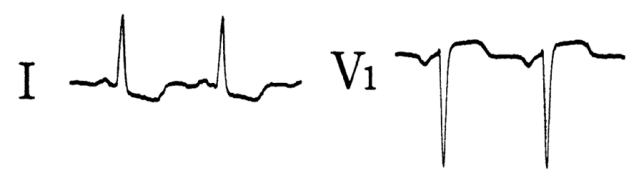<smiles>C=C(CCC)CCCC(C)CCCC</smiles><smiles>[Y]C1CCCCC1CCC</smiles><smiles>C#CCC(C)CCCC(C)CCC</smiles>

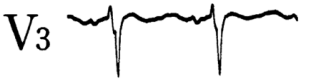<smiles>[R11]C(C)CCC(C)CCC</smiles><smiles>CCCC1CCC([Te])C1[Al]C</smiles>

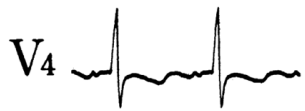

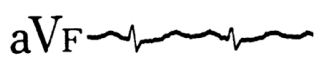

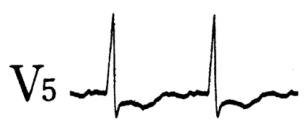

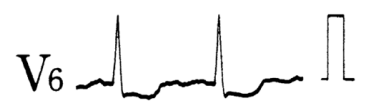

B

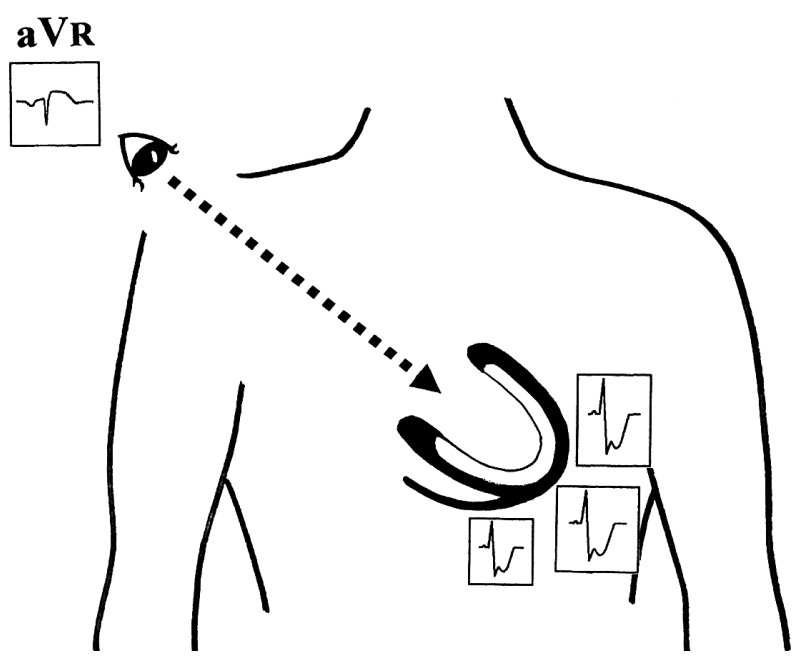

Figure 2. Electrocardiogram (ECG) of left main and/or 3-vessel disease (LM/3VD). (A) Representative ECG on admission in patients with LM/3VD (Reproduced with permission from Am J Cardiol 2005; 95: 1366-1369) ST-segment depression is found in leads I, II, aVL, $\mathrm{aVF}$, and $\mathrm{V}_{4}$ to $\mathrm{V}_{6}$, whereas ST-segment elevation of $0.15 \mathrm{mV}$ occurs in lead aVR. Coronary angiography showed total occlusion of the right coronary artery (segment 3 ) and $75 \%$ stenosis of the left main trunk, left anterior descending coronary artery (segment 6), and left circumflex coronary artery (segment 11). (B) LM/3VD is associated with extensive ischemia of the endocardial side of the left ventricle (white part of the Figure), resulting in ST-segment depression in most leads, but ST-segment elevation in lead aVR (a so-called "cavity lead"). focused on ST-segment deviation in leads other than $\mathrm{aVR}$; that is, clinicians have used an "11-lead" ECG, neglecting lead $\mathrm{aVR}$, $6-15$ Therefore, the clinical significance of STsegment deviation in lead $\mathrm{aVR}$ in patients with NSTE-ACS remains poorly understood.

Several studies have found analysis of lead $\mathrm{aVR}$ to be useful for the evaluation of NSTE-ACS $!^{1-21}$ Gorgels et al. reported that ST-segment elevation in lead aVR accompanied by ST-segment depression in leads I, II and $\mathrm{V}_{4}$ to $\mathrm{V}_{6}$ during episodes of angina is highly suggestive of LM/3VD in patients with rest angina ${ }^{17}$ Barrabés et al demonstrated that the presence of ST-segment elevation in lead aVR predicts the risk of in-hospital death in patients with a first nonST-segment elevation acute myocardial infarction. ${ }^{18}$ In that study, ST-segment elevation in lead aVR was also related to $\mathrm{LM} / 3 \mathrm{VD}$; however, coronary angiography was performed in only $56 \%$ of the subjects within 6 months after infarction.

Early identification of patients with LM/3VD, whose prognosis remains poor, is an important factor in selecting the optimal treatment strategy for patients with NSTE-ACS. Because combined antiplatelet therapy with aspirin and clopidogrel improves outcomes in patients with NSTE-ACS, current international clinical guidelines for the management of NSTE-ACS recommended the early initiation of treatment with this combination of drugs2,22 However, such combined therapy can increase the risk of perioperative bleeding and the need for blood transfusions in patients undergoing immediate coronary artery bypass graft surgery (CABG) ${ }^{23}$ Therefore, early (ie, before angiography), accurate, non-invasive identification of patients with $L M / 3 \mathrm{VD}$ is thus a major clinical issue with important therapeutic implications. We examined the predictors of LM/3VD on the admission ECG in patients with NSTE-ACS who underwent coronary angiography in the acute phase ${ }^{19}$ ST-segment elevation in lead $a V_{R}$ was found to be highly suggestive of LM/3VD (Figure 2A), and the converse was also true, ie, the absence of this finding was rarely associated with LM/3VD 19 Furthermore, ST-segment elevation in lead $a V_{R}$ on admission has been shown to have higher prognostic value than ST-segment depression in other leads in patients with NSTE-ACS both in some single-centers and a multicenter trial ${ }^{18-21}$ However, Yan et al recently reported that ST-segment elevation in lead $\mathrm{aVR}$ was associated with higher unadjusted in-hospital and 6-month mortality, but did not provide better prognostic information than comprehensive risk stratification using the validated GRACE (Global Registry of Acute Coronary Events) risk model24 This conclusion was based on an analysis of data from 5,064 patients in the GRACE study. The inconsistent prognostic values of ST-segment elevation in lead aVR may be explained by the lower prevalence of ST-segment elevation in lead $\mathrm{aVR}$ in the study by $\mathrm{Yan}_{\mathrm{a}} \mathrm{et}^{24}$ (only $7.3 \%$ ) than in previous studies $(27-33 \%)^{18-20}$; the lower prevalence in the former may have limited the power of the study to explore the relation between ST-segment elevation in lead $\mathrm{aVR}$ and outcomes reliably 25 In patients with NSTE-ACS, disease severity on coronary angiography, which varies depending on the type of study and inclusion criteria, influences the prognostic implications of ST-segment elevation in lead aVR. Moreover, among patients with NSTE-ACS who have $\mathrm{ST}$-segment elevation in lead $\mathrm{aVR}$ on the admission ECG, those in whom ST-segment elevation in lead $\mathrm{aVR}$ persists $6 \mathrm{~h}$ after admission despite intensive medical treatment have a higher risk of adverse events at 30 days than those in whom ST-segment elevation in lead $\mathrm{aVR}$ rapidly resolves 

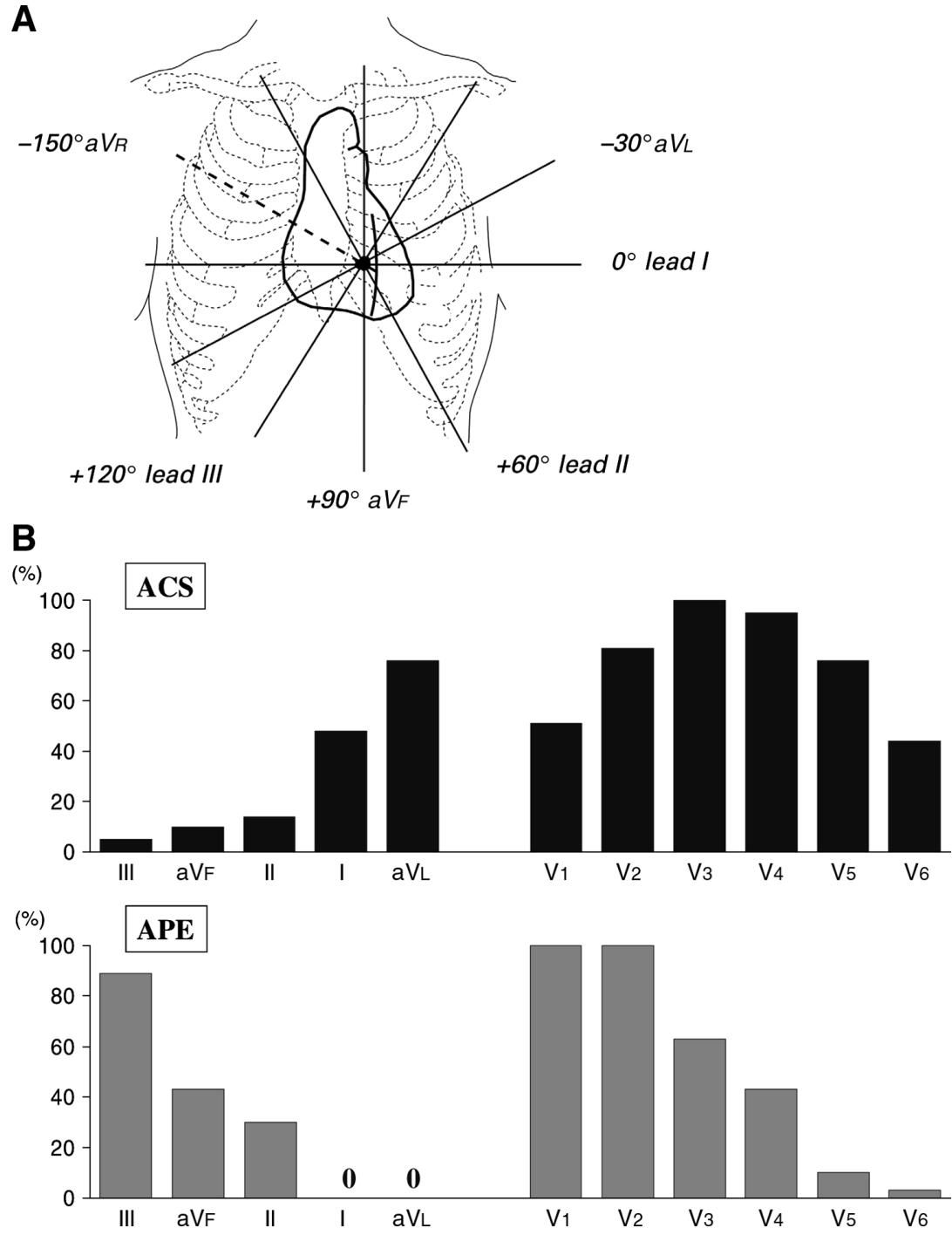

Figure 3. (A) Rearrangement of limb leads. Rearrangement of the limb leads in the order of III, $\mathrm{aVF}$, II, I and $\mathrm{aV}_{\mathrm{L}}$ (ie, in the order that the regions face the heart) facilitates an understanding of their spatial relationship to the heart (Modified reproduced with permission from Heart 2000; 83: 657-660). (B) Prevalence of negative $\mathrm{T}$ waves in patients with acute coronary syndrome (ACS) and those with acute pulmonary embolism (APE) (Modified reproduced with permission from Am J Cardiol 2007; 99: 817-821). In the setting of ACS, (1) in the limb leads, negative $\mathrm{T}$ waves were rare in the inferior leads, especially in lead III, whereas negative $\mathrm{T}$ waves were frequently observed in leads I and $\mathrm{aVL}$, particularly the latter; (2) in the precordial leads, negative $\mathrm{T}$ waves were mainly found in leads $V_{3}$ and $V_{4}$. The distribution of negative $T$ waves appears to reflect the extent of severe ischemia caused by LAD disease. In the APE setting: (1) in the limb leads, negative $\mathrm{T}$ waves frequently appeared in the inferior leads, especially lead III, but were not found in lead I or $\mathrm{aV}_{\mathrm{L}} ;(2)$ in the precordial leads, negative $T$ waves were observed mainly in leads $V_{1}$ and $\mathrm{V}_{2}$, and gradually decreased from leads $\mathrm{V}_{3}$ to V6. Dilatation of the right ventricle is thought to extend to region(s) facing the lead(s) with negative $\mathrm{T}$ waves. after admission.6 The former have more severe LM/3VD on coronary angiography than the latter.

\section{Possible Mechanism of ST-Segment Elevation in Lead aVR}

Lead $\mathrm{a} \mathrm{V}_{\mathrm{R}}$ has a unique position because the positive pole is oriented to the right upper side of the heart ${ }^{27,28}$ The mechanisms underlying ST-segment elevation in lead aVR might differ between ST-segment elevation and non-ST-segment elevation ACSs. In ST-segment elevation ACS, ST-segment elevation in lead $\mathrm{aVR}$ might reflect transmural ischemia in the basal septum, often caused by obstruction of left-main or the proximal left anterior descending coronary artery (LAD) with involvement of the first septal branch, resulting in a superior orientation of the ST-segment vector? 29,30 In NSTE$\mathrm{ACS}$, lead $\mathrm{aVR}$ looks into the left ventricular cavity from the right shoulder (Figure 2B). Lead $\mathrm{a} \mathrm{V}_{\mathrm{R}}$ is therefore referred to as a "cavity lead" and ST-segment elevation in this lead might reflect global subendocardial ischemia. When circumferential ischemia, often associated with LM/3VD, is accompanied by severe extensive ischemia of the subendocardial layer, the ST-segment vector is directed to the right shoulder, resulting in ST-segment elevation in lead aVR? 1

Conventionally, non-ST-segment elevation ACS is defined without considering ST-segment deviation in lead a VR. However, ST-segment elevation in lead $\mathrm{aVR}$ is a very valuable marker in "so-called" non-ST-segment elevation ACS? ${ }^{2}$

\section{QRS Duration}

Although electrocardiographic assessment of myocardial ischemia is usually based on ST-segment deviation, QRS prolongation has been shown to be more sensitive than STsegment changes for the detection of myocardial ischemia ${ }^{33}$ Several studies have found that that exercise-induced QRS prolongation is related to the severity and extent of coronary artery disease ${ }^{34}$ However, the relation between QRS duration on the admission ECG and the severity and extent of coronary artery disease has not been explored previously in patients with NSTE-ACS. We recently reported that not only ST-segment elevation in lead $\mathrm{aVR}$ and positive-troponin $\mathrm{T}$ on admission but also prolonged QRS duration, ie, maximal QRS duration $>90 \mathrm{~ms}$, on the admission ECG (QRS duration was measured from the beginning of the $\mathrm{Q}$ wave until the cut-point between the baseline and the perpendicular line starting from the end of the $\mathrm{S}$ wave [J point]) were highly suggestive of LM/3VD in patients with NSTE-ACS 35 QRS prolongation is most likely to be caused by extensive isch- 
A

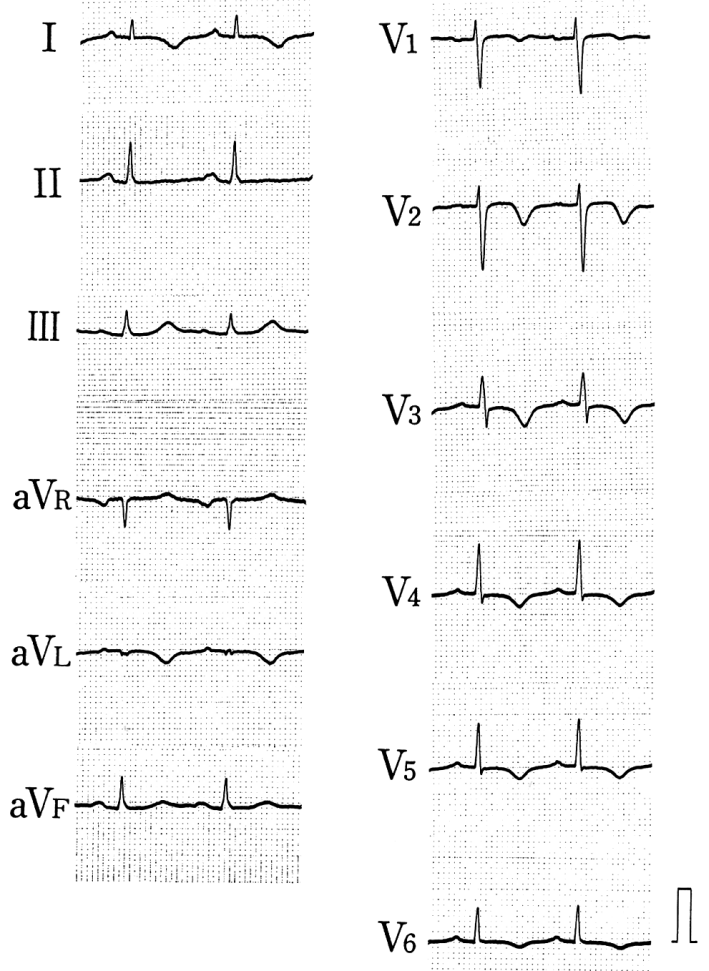

B
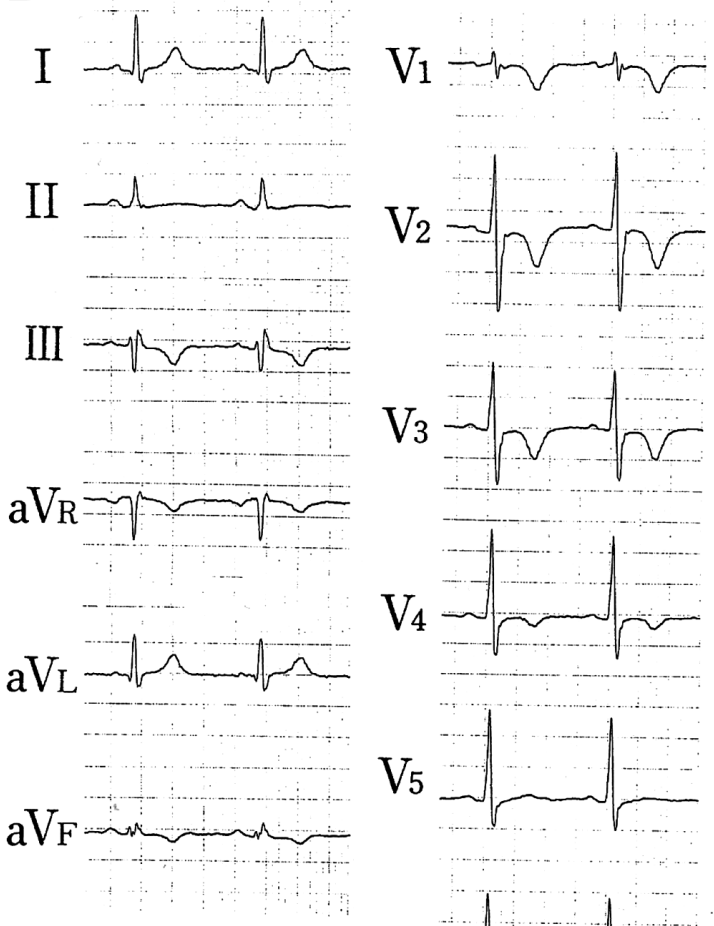

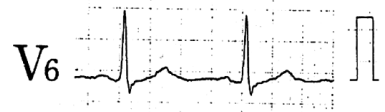

Figure 4. Representative electrocardiograms on admission of acute coronary syndrome (ACS) and acute pulmonary embolism (APE) (Reproduced with permission from Am J Cardiol 2007; 99: 817-821). (A) ACS. Negative T waves were seen in leads I, a $V_{L}$ and $V_{1}$ to $V_{6}$. Coronary angiography revealed $90 \%$ stenosis of the left anterior descending artery (segment 6). (B) APE. Negative $\mathrm{T}$ waves were seen in leads III, $\mathrm{aVF}$ and $\mathrm{V}_{1}$ to $\mathrm{V}_{4}$. A computed tomographic scan of the chest showed multiple filling defects in the main right and left pulmonary arteries. Lung perfusion scintigraphy revealed filling defects in the right upper, right middle and left upper lung fields.

emia. Experimental studies have reported that myocardial ischemia results in slow conduction velocity in ischemic areas ${ }^{36}$ Such decreased conduction velocity is apparently a consequence of regional hyperkalemia, caused by leakage of potassium from ischemic cells. This decreased conduction velocity associated with myocardial ischemia is manifested as QRS prolongation on the surface ECG.

\section{Combined Prognostic Utility of ECG and Biomarkers}

Greater ST-segment deviation has been shown to be associated with a higher levels of cardiac troponins?,13,14 Troponins $\mathrm{T}$ and I are recognized as powerful predictors of outcomes in patients with NSTE-ACS?,3,14 Several studies have found that ST-segment depression in leads other than lead $\mathrm{aVR}$ combined with troponin levels on admission is useful for the evaluation of NSTE-ACS $11,14,15$ Holmvang et al showed that baseline values of troponins $\mathrm{T}$ and $\mathrm{I}$ combined with ST-T changes at presentation were useful for predicting death or myocardial infarction at 30 days in patients with unstable coronary artery disease ${ }^{15}$ Kaul et al noted that positive troponin $\mathrm{T}$ was associated with a higher risk of death or myocardial infarction at 6 months within each ST-segment depression category (no, $0.1 \mathrm{mV}$, and $0.2 \mathrm{mV}$ ST-segment depression) among patients with NSTE-ACS!4 ST-segment depression and troponins are markers of different pathophysiological mechanisms implicated in NSTE-
ACS. A combination of these 2 variables may therefore provide higher prognostic accuracy than either variable alone. Furthermore, ST-segment elevation in lead aVR combined with troponin $\mathrm{T}$ is an incrementally stronger predictor of adverse outcomes at 90 days as compared with either of these variables alone in patients with NSTE-ACS20 These findings emphasize that ECG and biomarkers are complementary for the assessment of risk in patients with NSTEACS and suggest that both should be employed in prognosis and decision making.

\section{Negative T Waves in NSTE-ACS}

In patients with NSTE-ACS, ST-segment changes are considered the most important ECG feature, but T-wave changes have been shown to be more common than STsegment changes $6,37,38$ A meta-analysis of 10,150 patients with NSTE-ACS demonstrated that women were significantly more likely to have negative $\mathrm{T}$ waves $3^{38} \mathrm{~T}$-wave changes have had little prognostic value in several large randomized clinical trials? Savonitto et al reported that isolated negative $\mathrm{T}$ waves on the admission ECG were associated with less severe coronary disease and a relatively benign prognosis as compared with ST-segment changes among patients with ACS? However, none of these studies used a quantitative approach to T-wave analysis. Holmvang et al noted that negative $T$ waves in $\geq 5$ leads at randomization was an independent predictor of death or myocardial infarction at 30 
days in patients with NSTE-ACS ${ }^{15}$ Jacobsen et al also suggested that patients with $\geq 6$ leads showing abnormal $T$ waves with concomitant ST-segment depression had a higher risk of death or myocardial infarction at 1 year when they did not receive early coronary angiography in patients with NSTEACS 39 Negative $T$ waves can actually be preceded by a transient ST-segment elevation that resolves by the time the ECG is recorded. Therefore, the ischemia-related artery can be predicted on the basis of the distribution of negative $\mathrm{T}$ waves. For example, negative $\mathrm{T}$ waves in precordial leads are most likely caused by LAD disease. 40

\section{Electrocardiographic Differential Diagnosis of ACS and Acute Pulmonary Embolism (APE)}

Negative $\mathrm{T}$ waves in precordial leads also frequently appear in patients with APE41-44 The electrocardiographic manifestations of APE include rhythm and condition disturbances and changes in $\mathrm{P}$ waves, QRS complexes or T waves. These abnormalities have been shown to be highly variable and frequently transient 41,42 Of many ECG abnormalities associated with APE, negative $T$ waves are the most common as well as the most persistent change ${ }^{41-44}$ Symptoms of APE, such as chest pain or dyspnea, are non-specific and are often difficult to differentiate from symptoms of ACS44,45 The majority of preventable deaths associated with APE have been ascribed to missed diagnoses rather than to failure to respond to available therapies. 45 Elevated cardiac troponin levels are found in high-risk APE as well as in ACS; this variable is therefore of limited value for differential diagnosis. ${ }^{46}$ Echocardiography is useful for discriminating between high-risk APE and ACS47 However, echocardiography has several technical limitations, and fully assessable echocardiographic images are not always obtained.

We examined electrocardiographic differences between patients with APE and ACS who had negative T waves in $\geq 2$ contiguous precordial leads ( $\mathrm{V}_{1}$ to $\left.\mathrm{V}_{4}\right)^{48}$ The distribution of negative $\mathrm{T}$ waves obviously differed between APE and $\mathrm{ACS}$, and this difference was useful for differential diagnosis (Figures 3A,B). The presence of negative $\mathrm{T}$ waves in both leads III and V1 strongly suggested APE (the sensitivity and specificity of this ECG finding for the diagnosis of APE were $88 \%$ and $99 \%$, respectively), thereby allowing APE to be simply but accurately differentiated from ACS (Figures 4A,B). The diagnosis of APE relies predominantly on the magnitude of clinical suspicion. This simple ECG criterion may help to correctly diagnose APE.

In the setting of ACS, the presence of negative $\mathrm{T}$ waves in lead $V_{1}$ may suggest ischemia of the upper paraseptal region, probably due to proximal LAD disease. 49 When the LAD is proximally occluded, ST-segment depression in inferior leads can be caused by reciprocal changes associated with transmural ischemia in the high anterobasal region 30 If an LAD that wraps around the apex and supplies the inferior wall (a so-called "wrapped LAD") is proximally occluded, ST-segment deviation in inferior leads has been shown to be minimally depressed or isoelectric; consequently, negative $\mathrm{T}$ waves in these leads are rarely observed in this situation ${ }^{50,51}$ In contrast, a distally occluded LAD that wraps around the apex, in which the injury current is directed horizontally and therefore does not influence STsegment deviation in inferior leads, is thought to be prerequisite for ST-segment elevation in inferior leads 51 The incidence of ST-segment elevation in inferior leads has been reported to range from only $5 \%$ to $16 \%$ in anterior acute myocardial infarction. Consequently, negative $\mathrm{T}$ waves in lead III are usually not accompanied by negative $\mathrm{T}$ waves in lead $\mathrm{V}_{1}$ in patients with ACS.

The mechanism responsible for the occurrence of negative $\mathrm{T}$ waves after APE is not completely understood, but may involve the development of acute cor pulmonale caused by enlargement of the right ventricle due to rapid right ventricular pressure overload, potentially leading to severe ischemia of the right ventricle ${ }^{4}{ }^{4}$ Negative $T$ waves in leads III, $V_{1}$ and $V_{2}$ are very common in patients with APE.$^{48}$ Lead III faces the inferior region of the right ventricle, and leads $\mathrm{V}_{1}$ and $\mathrm{V}_{2}$ face the anterior region of the right ventricle. With increasing severity of right heart failure and dilation of the right ventricle towards the left, negative $\mathrm{T}$ waves are thought to move in a left direction, ie, from lead $V_{1}$ to $V_{6}$ in the precordial leads and from lead III to $\mathrm{aVF}$ to II lead in the limb leads (Figure 3A). The number of leads with negative $\mathrm{T}$ waves is thus closely associated with the severity of APE, as well as with adverse in-hospital outcomes.43 Patients with severe APE may be more likely to be given a misdiagnosis of ACS caused by the LAD disease, because negative T waves appear most commonly in the precordial leads.

\section{Concluding Remark}

ECG wave patterns are influenced by a number of factors, including physique and dimensions of the thorax. ECG diagnosis is challenging in patients with secondary ST-T changes caused by bundle-branch block or cardiac hypertrophy, those with Wolff-Parkinson-White syndrome and those who are receiving ventricular pacing or digitalis. The ECG should be used with a thorough understanding of these drawbacks. Despite the development of improved diagnostic strategies, the ECG remains an essential clinical tool for the evaluation of ACS because it is inexpensive, readily available, and noninvasive.

\section{Acknowledgments}

The authors thank the co-workers at the Division of Cardiology, Yokohama City University Medical Center.

\section{References}

1. Cannon CP, Braunwald E. Unstable angina and non-ST elevation myocardial infarction. In: Braunwald E, editor. Heart disease: A Textbook of Cardiovascular Medicine. $8^{\text {th }}$ ed. Philadelphia: WB Saunders Co; 2008; 1319-1351.

2. Anderson JL, Adams CD, Antman EM, Bridges CR, Califf RM, Casey $\mathrm{DE} \mathrm{Jr}$, et al. ACC/AHA guidelines for the management of patients with unstable angina/non-ST-segment elevation myocardial infarction: A report of the American College of Cardiology/American Heart Association Task Force on Practice Guidelines. Circulation 2007; 116: $803-877$.

3. Westerhout CM, Fu Y, Lauer MS, James S, Armstrong PW, AlHattab E, et al; GUSTO-IV ACS Trial Investigators. Short- and longterm risk stratification in acute coronary syndromes: The added value of quantitative ST-segment depression and multiple biomarkers. J Am Coll Cardiol 2006; 48: 939-947.

4. Nakachi T, Kosuge M, Hibi K, Ebina T, Hashiba K, Mitsuhashi T, et al. C-reactive protein elevation and rapid angiographic progression of nonculprit lesion in patients with non-ST-segment elevation acute coronary syndrome. Circ J 2008; 72: 1953-1959.

5. Pitsavos C, Kourlaba G, Panagiotakos DB, Kogias Y, Mantas Y, Chrysohoou $\mathrm{C}$, et al. Association of creatinine clearance and inhospital mortality in patients with acute coronary syndromes: The GREECS study. Circ J 2007; 71: 9-14.

6. Cannon CP, McCabe CH, Stone PH, Rogers WJ, Schactman M, Thompson BW, et al. The electrocardiogram predicts one-year outcome of patients with unstable angina and non-Q wave myocardial infarction: Results of the TIMI III registry ECG ancillary study. $J$ Am 
Coll Cardiol 1997; 30: 133 - 140.

7. Holmvang L, Clemmensen P, Wagner G, Grande P. Admission standard electrocardiogram for early risk stratification in patients with unstable coronary artery disease not eligible for acute revascularization therapy: A TRIM substudy. ThRombin Inhibition in Myocardial Infarction. Am Heart J 1999; 137: 24-33.

8. Savonitto S, Ardissino D, Granger CB, Morando G, Prando MD, Mafrici A, et al. Prognostic value of the admission electrocardiogram in acute coronary syndromes. JAMA 1999; 281: 707-713.

9. Kosuge M, Kimura K, Ishikawa T, Shimizu T, Hibi K, Nozawa N, et al. Clinical implications of persistent ST segment depression after admission in patients with non-ST segment elevation acute coronary syndrome. Heart 2005; 91: 95-96.

10. Atar S, Fu Y, Wagner GS, Rosanio S, Barbagelata A, Birnbaum Y. Usefulness of ST depression with T-wave inversion in leads V(4) to $\mathrm{V}(6)$ for predicting one-year mortality in non-ST-elevation acute coronary syndrome (from the Electrocardiographic Analysis of the Global Use of Strategies to Open Occluded Coronary Arteries IIB Trial). Am J Cardiol 2007; 99: 934-938.

11. Ben-Dor I, Hasdai D, Behar S, Zahger D, Leor J, Hammerman H, et al. Prognostic implications of increased cardiac biomarkers and ST segment depression in non-ST elevation acute coronary syndromes: Lessons from the acute coronary syndrome Israeli survey (ACSIS) 2002. Heart 2006; 92: 547-548.

12. Savonitto S, Cohen MG, Politi A, Hudson MP, Kong DF, Huang Y, et al. Extent of ST-segment depression and cardiac events in non-STsegment elevation acute coronary syndromes. Eur Heart J 2005; 26: $2106-2113$.

13. Holmvang L, Clemmensen P, Lindahl B, Lagerqvist B, Venge P, Wagner G, et al. Quantitative analysis of the admission electrocardiogram identifies patients with unstable coronary artery disease who benefit the most from early invasive treatment. J Am Coll Cardiol 2003; 41: 905-915.

14. Kaul P, Newby LK, Fu Y, Hasselblad V, Mahaffey KW, Christenson $\mathrm{RH}$, et al; PARAGON-B Investigators. Troponin $\mathrm{T}$ and quantitative ST-segment depression offer complementary prognostic information in the risk stratification of acute coronary syndrome patients. $J \mathrm{Am}$ Coll Cardiol 2003; 41: 371 - 380.

15. Holmvang L, Lüscher MS, Clemmensen P, Thygesen K, Grande P. Very early risk stratification using combined ECG and biochemical assessment in patients with unstable coronary artery disease (A thrombin inhibition in myocardial ischemia [TRIM] substudy). The TRIM Study Group. Circulation 1998; 98: 2004-2009.

16. Detrano R, Gianrossi R, Mulvihill D, Lehmann K, Dubach P, Colombo A, et al. Exercise-induced ST segment depression in the diagnosis of multivessel coronary disease: A meta analysis. J Am Coll Cardiol 1989; 14: 1501 - 1508 .

17. Gorgels AP, Vos MA, Mulleneers R, de Zwaan C, Bar FW, Wellens HJ. Value of the electrocardiogram in diagnosing the number of severely narrowed coronary arteries in rest angina pectoris. $\mathrm{Am} J$ Cardiol 1993; 72: 999-1003.

18. Barrabés JA, Figueras J, Moure C, Cortadellas J, Soler-Soler J. Prognostic value of lead aVR in patients with a first non-ST-segment elevation acute myocardial infarction. Circulation 2003; 108: 814-819.

19. Kosuge M, Kimura K, Ishikawa T, Ebina T, Shimizu T, Hibi K, et al. Predictors of left main or three-vessel disease in patients who have acute coronary syndromes with non-ST-segment elevation. Am J Cardiol 2005; 95: 1366-1369.

20. Kosuge M, Kimura K, Ishikawa T, Ebina T, Hibi K, Tsukahara K, et al. Combined prognostic utility of ST segment in lead aVR and troponin $\mathrm{T}$ on admission in non-ST-segment elevation acute coronary syndromes. Am J Cardiol 2006; 97: 334-339.

21. Sakai S, Gavard JA, Stocke K, Chaitman BR; for the GUARDIAN Investigators. Analysis of ST-segment shift in lead aVR improves short-term prognostic risk stratification in acute coronary syndrome. J Am Coll Cardiol 2003; 41: 402.

22. Angiolillo DJ, Guzman LA, Bass TA. Current antiplatelet therapies: Benefits and limitations. Am Heart J 2008; 156: S3-S9.

23. Berger JS, Frye CB, Harshaw Q, Edwards FH, Steinhubl SR, Becker $\mathrm{RC}$. Impact of clopidogrel in patients with acute coronary syndromes requiring coronary artery bypass surgery: A multicenter analysis. $J \mathrm{Am}$ Coll Cardiol 2008; 52: $1693-1701$.

24. Yan AT, Yan RT, Kennelly BM, Anderson FA Jr, Budaj A, LopezSendon J, et al; GRACE Investigators. Relationship of ST elevation in lead aVR with angiographic findings and outcome in non-ST elevation acute coronary syndromes. Am Heart J 2007; 154: 71-78.

25. Barrabés JA, Figueras J. Does lead aVR contain prognostic information in patients with non-ST-elevation acute coronary syndromes? Am Heart J 2008; 155: e11.

26. Kosuge M, Ebina T, Hibi K, Endo M, Komura N, Hashiba K, et al.
ST-segment elevation resolution in lead aVR: A strong predictor of adverse outcomes in patients with non-ST-segment elevation acute coronary syndrome. Circ J 2008; 72: 1047-1053.

27. Menown IB, Adgey AA. Improving the ECG classification of inferior and lateral myocardial infarction by inversion of lead aVR. Heart 2000; 83: 657-660.

28. Yu PN, Stewart JM. Subendocardial myocardial infarction with special reference to the electrocardiographic changes. Am Heart J 1950; 39: $862-880$.

29. Yamaji H, Iwasaki K, Kusachi S, Murakami T, Hirami R, Hamamoto $\mathrm{H}$, et al. Prediction of acute left main coronary artery obstruction by 12-lead electrocardiography: ST segment elevation in lead aVR with less ST segment elevation in lead V(1). J Am Coll Cardiol 2001; 38: $1348-1354$.

30. Engelen DJ, Gorgels AP, Cheriex EC, De Muinck ED, Ophuis AJ, Dassen WR, et al. Value of the electrocardiogram in localizing the occlusion site in the left anterior descending coronary artery in acute anterior myocardial infarction. J Am Coll Cardiol 1999; 342: $389-$ 395.

31. Savonitto S, Cohen MG, Politi A, Hudson MP, Kong DF, Huang Y, et al. Extent of ST-segment depression and cardiac events in non-STsegment elevation acute coronary syndromes. Eur Heart J 2005; 26: $2106-2113$

32. Gorgels AP, Engelen DJ, Wellens HJ. Lead aVR, a mostly ignored but very valuable lead in clinical electrocardiography. $\mathrm{J} \mathrm{Am} \mathrm{Coll} \mathrm{Cardiol}$ 2001; 38: 1355-1356.

33. Cantor AA, Goldfarb B, Ilia R. QRS prolongation: A sensitive marker of ischemia during percutaneous transluminal coronary angioplasty. Catheter Cardiovasc Interv 2000; 50: 177-183.

34. Michaelides A, Ryan JM, VanFossen D, Pozderac R, Boudoulas H. Exercise-induced QRS prolongation in patients with coronary artery disease: A marker of myocardial ischemia. Am Heart J 1993; 126: $1320-1325$

35. Kosuge M, Kimura K, Ishikawa T, Uchino K, Ebina T, Hibi K, et al. Early, simple, noninvasive predictors of left main or 3-vessel disease in patients with non-ST-segment elevation acute coronary syndromes. Circ J 2009 (in press).

36. Holland RP, Brooks H. The QRS complex during myocardial ischemia. J Clin Invest 1976; 57: 541-550.

37. Jacobsen MD, Wagner GS, Holmvang L, Macfarlane PW, Näslund U, Grande $\mathrm{P}$, et al. Clinical significance of abnormal $\mathrm{T}$ waves in patients with non-ST-segment elevation acute coronary syndromes. Am J Cardiol 2001; 88: $1225-1229$.

38. O'Donoghue M, Boden WE, Braunwald E, Cannon CP, Clayton TC, de Winter RJ, et al. Early invasive vs conservative treatment strategies in women and men with unstable angina and non-ST-segment elevation myocardial infarction: A meta-analysis. JAMA 2008; 300: $71-$ 80.

39. Jacobsen MD, Wagner GS, Holmvang L, Kontny F, Wallentin L, Husted S, et al. Quantitative T-wave analysis predicts 1 year prognosis and benefit from early invasive treatment in the FRISC II study population. Eur Heart J 2005; 26: 112-118.

40. Renkin J, Wijns W, Ladha Z, Col J. Reversal of segmental hypokinesis by coronary angioplasty in patients with unstable angina, persistent $T$ wave inversion, and left anterior descending coronary artery stenosis: Additional evidence for myocardial stunning in humans. Circulation 1990; 82: 913-921.

41. Stein PD, Dalen JE, McIntyre KM, Sasahara AA, Wenger NK, Willis PW 3rd. The electrocardiogram in acute pulmonary embolism. Prog Cardiovasc Dis 1975; 17: 247-257.

42. Goldhaber SZ. Pulmonary embolism. In: Braunwald E, editor. Heart Disease: A Textbook of Cardiovascular Medicine. $8^{\text {th }}$ ed. Philadelphia: WB Saunders Co; 2008; $1863-1881$.

43. Kosuge M, Kimura K, Ishikawa T, Ebina T, Hibi K, Tsukahara K, et al. Prognostic significance of inverted $T$ waves in patients with acute pulmonary embolism. Circ J 2006; 70: 750-755.

44. Stein PD, Terrin ML, Hales CA, Palevsky HI, Saltzman HA, Thompson BT, et al. Clinical, laboratory, roentgenographic, and electrocardiographic findings in patients with acute pulmonary embolism and no pre-existing cardiac or pulmonary disease. Chest 1991; 100: $598-603$.

45. Fedullo PF, Tapson VF. The evaluation of suspected pulmonary embolism. N Engl J Med 2003; 349: 1247-1256.

46. Kline JA, Zeitouni R, Marchick MR, Hernandez-Nino J, Rose GA. Comparison of 8 biomarkers for prediction of right ventricular hypokinesis 6 months after submassive pulmonary embolism. Am Heart $J$ 2008; 156: 308-314

47. Toosi MS, Merlino JD, Leeper KV. Prognostic value of the shock index along with transthoracic echocardiography in risk stratification of patients with acute pulmonary embolism. Am J Cardiol 2008; 101: 
$700-705$.

48. Kosuge M, Kimura K, Ishikawa T, Ebina T, Hibi K, Kusama I, et al. Electrocardiographic differentiation between acute pulmonary embolism and acute coronary syndromes on the basis of negative T waves. Am J Cardiol 2007; 99: 817-821.

49. Ben-Gal T, Sclarovsky S, Herz I, Strasberg B, Zlotikamien B, Sulkes $\mathrm{J}$, et al. Importance of the conal branch of the right coronary artery in patients with acute anterior wall myocardial infarction: Electrocardiographic and angiographic correlation. J Am Coll Cardiol 1997; 29: 506-511.
50. Porter A, Sclarovsky S, Ben-Gal T, Herz I, Solodky A, Sagie A. Value of T-wave direction with lead III ST-segment depression in acute anterior wall myocardial infarction: Electrocardiographic prediction of a "wrapped" left anterior descending artery. Clin Cardiol 1998; 21: $562-566$.

51. Sasaki K, Yotsukura M, Sakata K, Yoshino H, Ishikawa K. Relation of ST-segment changes in inferior leads during anterior wall acute myocardial infarction to length and occlusion site of the left anterior descending coronary artery. Am J Cardiol 2001; 87: 1340-1345. 